\title{
Cellular Basis for Blunted Volume Expansion Natriuresis in Experimental Nephrotic Syndrome
}

Jean-Pierre Valentin, Changbin Qiu, William P. Muldowney, Wei-Zhong Ying, David G. Gardner, and Michael H. Humphreys Division of Nephrology, San Francisco General Hospital, and the Metabolic Research Unit, University of California San Francisco, San Francisco, California 94110

\section{Abstract}

Experimental nephrotic syndrome results in sodium retention, reflecting, at least in part, an intrinsic defect in renal sodium handling in the distal nephron. We studied the relationships among plasma atrial natriuretic peptide (ANP) concentration, sodium excretion $\left(U_{\mathrm{Na}} V\right)$, and urinary cyclic GMP excretion $\left(U_{\text {CGMP }} V\right)$ in vivo, and the responsiveness of isolated glomeruli and inner medullary collecting duct (IMCD) cells to ANP in vitro, in rats with adriamycin nephrosis $(6-7 \mathrm{mg} / \mathrm{kg}$ body weight, intravenously). 3-5 wk after injection, rats were proteinuric and had a blunted natriuretic response to intravenous infusion of isotonic saline, $2 \%$ body weight given over $5 \mathrm{~min} .30$ min after onset of the infusion, plasma ANP concentrations were elevated in normals and were even higher in nephrotics. Despite this, nephrotic animals had a reduced rate of $U_{\text {cGMP }} V$ after the saline infusion, and accumulation of cGMP by isolated glomeruli and IMCD cells from nephrotic rats after incubation with ANP was significantly reduced compared to normals. This difference was not related to differences in binding of ${ }^{125}$ I-ANP to IMCD cells, but was abolished when cGMP accumulation was measured in the presence of $10^{-3} \mathrm{M}$ isobutylmethylxanthine or zaprinast (M\&B 22,948), two different inhibitors of cyclic nucleotide phosphodiesterases (PDEs). Infusion of zaprinast $(10 \mu \mathrm{g} / \mathrm{min})$ into one renal artery of nephrotic rats normalized both the natriuretic response to volume expansion and the increase in $U_{\text {CGMP }} V$ from the infused, but not the contralateral, kidney.

These results show that, in adriamycin nephrosis, blunted volume expansion natriuresis is associated with renal resistance to ANP, demonstrated both in vivo and in target tissues in vitro. The resistance does not appear related to a defect in binding of the peptide, but is blocked by PDE inhibitors, suggesting that enhanced cGMP-PDE activity may account for resistance to the natriuretic actions of ANP observed in vivo. This defect may represent the intrinsic sodium transport abnormality linked to sodium retention in nephrotic syndrome. (J. Clin. Invest. 1992.90:1302-1312.) Key words: atrial natriuretic peptide $•$ cyclic guanosine monophosphate $\cdot$ glomeruli • inner medullary collecting duct $\bullet$ phosphodiesterase $\bullet$ resistance

Portions of this work have been published in abstract form (1990. $J$. Am. Soc. Nephrol. 1:418; 1991. J. Am. Soc. Nephrol. 2:421).

Address reprint requests to Dr. Humphreys, Division of Nephrology, Room 350, Building 100, San Francisco General Hospital, San Francisco, CA 94110.

Received for publication 8 January 1992 and in revised form 17 April 1992.

J. Clin. Invest.

(c) The American Society for Clinical Investigation, Inc.

$0021-9738 / 92 / 10 / 1302 / 11 \quad \$ 2.00$

Volume 90, October 1992, 1302-1312

\section{Introduction}

Abnormal sodium metabolism leading to the pathological retention of sodium is a hallmark of both clinical and experimental nephrotic syndrome. Two major theories have been offered to account for the development of nephrotic edema (1). In one, functionally intact kidneys (with respect to sodium handling) retain sodium in response to signals arising from an underfilled circulation, the latter resulting from the transfer of plasma water to the interstitium secondary to hypoalbuminemia. According to this theory, the sodium retention occurs in a manner identical to that resulting from any other hypovolemic stimùlus, and is characterized in part by increases in filtration fraction and renal vascular resistance, enhanced fractional reabsorption of filtrate in the proximal tubule, heightened sympathetic renal nerve activity, activation of the renin-angiotensin system, and a reduced concentration of atrial natriuretic peptide (ANP $)^{1}$ in plasma. Numerous clinical and experimental observations document these patterns of renal function in at least some forms of nephrotic syndrome and thereby support the so-called "underfill" mechanism of edema formation (2-8).

An alternative theory argues that an intrinsic defect in the tubular handling of sodium by the nephrotic kidney results in increased reabsorption of filtered sodium, most likely in distal nephron segments. This increased reabsorption leads to positive sodium balance and extracellular fluid volume expansion whereby subsequent edema formation occurs on an "overflow" basis (1). Among the characteristics of renal function in this setting are a reduced filtration fraction, normal or decreased proximal reabsorption, and suppression of the reninangiotensin system. A number of observations are consistent with this formulation of the pathophysiology of nephrotic edema $(2,9-15)$.

Two models of experimental nephrosis have been particularly useful in exploring nephrotic sodium metabolism, those resulting from the intravenous administration of the aminonucleoside of puromycin (16) and of adriamycin (17). These agents regularly produce high-grade proteinuria in the rat without marked histologic change early, whereas glomerulosclerosis usually develops later in the course. For each agent, abnormalities in sodium handling can be shown to be intrinsic to the kidneys; unilateral administration leads to blunted natriuresis only of the involved, proteinuric kidney, a finding which supports the "overflow" model of nephrotic edema $(12,18)$.

Recent studies carried out in rats with nephrosis resulting from adriamycin administration have suggested that the ab-

1. Abbreviations used in this paper: ANP, atrial natriuretic peptide; AVP, arginine vasopressin; IBMX, isobutylmethylxanthine; IMCD, inner medullary collecting duct; PDE, phosphodiesterase; TFA, trifluoroacetic acid. 
normal sodium metabolism accompanying this disorder could reflect impaired responsiveness to circulating ANP (19-21). This resistance to the natriuretic action of ANP and the blunted natriuresis seen after volume expansion in these rats were shown to improve after renal denervation $(7,19)$. To explore these phenomena further, we have examined the relationship between the natriuretic response to extracellular fluid volume expansion and circulating ANP levels as well as urinary cyclic GMP excretion (an index of ANP bioactivity in the kidneys) in normal and nephrotic rats. In addition, we have explored more directly the effect of ANP on renal tissue from normal compared to nephrotic animals by using freshly dispersed glomeruli and inner medullary collecting duct (IMCD) cells to assess ANP binding activity and ANP-dependent cGMP accumulation. Our results support the hypothesis of relative ANP resistance in adriamycin nephrosis but suggest that this could reflect an intracellular defect that is not mediated solely through enhanced renal nerve activity.

\section{Methods}

All studies were carried out under protocols reviewed and approved by the Committee on Animal Research of the University of California, San Francisco. Experimental nephrotic syndrome was induced by the administration of $1 \mathrm{mg}$ of adriamycin (doxorubicin $\mathrm{HCl}$, Sigma) in 1 $\mathrm{ml}$ of normal saline by tail vein to male Sprague-Dawley rats weighing $150-180 \mathrm{~g}$ (6-7 $\mathrm{mg} / \mathrm{kg}$ body weight $)$. These animals were studied 3-5 wk later, at which time 24-h urinary protein excretion (collected in a metabolic cage) averaged $530 \pm 34$ (SE) $\mathrm{mg}(n=39)$; adriamycintreated rats in whom proteinuria was not quantitated had qualitative albuminuria of $4+$ by a color reagent (Ames Labstix, Miles Inc., Elkhart, IN). Normal control rats underwent no injection but were studied at the same age. All animals were allowed free access to standard laboratory rat diet and tap water and were housed in a constant temperature environment with a 12-h light-dark cycle.

In vivo studies. We carried out renal clearance studies in anesthetized rats that weighed between 250 and $320 \mathrm{~g}$ at the time of experimentation. For acute experimentation they were anesthetized with Inactin (Andrew Lockwood \& Assoc., Sturtevant, WI) $120 \mathrm{mg} / \mathrm{kg}$ intraperitoneally, and placed on a heated operating table to maintain rectal temperature at $37 \pm 0.5^{\circ} \mathrm{C}$. A tracheostomy tube was placed and fine polyethylene catheters were inserted into a femoral vein for infusion of solutions and into a femoral artery for obtaining blood samples and monitoring arterial blood pressure. Pressure was recorded with a Statham model P23id pressure transducer (Gould Instruments, Inc., Oxnard, CA) attached to a polygraph recorder (model 7D, Grass Instruments, Quincy, MA). Urine was collected into preweighed plastic vials via a flanged catheter inserted into the urinary bladder by means of a small suprapubic incision.

All animals received an intravenous infusion of normal saline at 2.4 $\mathrm{ml} / \mathrm{h}$ from the completion of surgery through the duration of the study. In most experiments this solution contained sufficient meglumine iothalamate (Conray 60, Mallinkrodt, Inc., St. Louis, MO) to permit the determination of the clearance of iothalamate $\left(C_{i o}\right)$ as an estimate of glomerular filtration rate (GFR). A 60-min interval elapsed after the completion of surgery to allow for equilibration of the infusion solution and recovery from surgical preparation. Then, two timed urine collections were obtained $\left(C_{1}, C_{2}\right)$ as was a $200-\mu$ l blood sample, collected in heparinized glass capillary tubes, at the midpoint of each period. We next administered a volume of normal saline equal to $2 \%$ of the rat's weight intravenously over a 5-min interval. In many cases, iothalamate was included in this saline infusion to minimize alterations in plasma iothalamate concentration, thereby permitting more accurate determination of $\mathrm{C}_{\mathrm{i}}$. Urine collections continued for three successive 10-min periods beginning with the onset of the infusion; they are termed $E_{1}$, $E_{2}$, and $E_{3}$. Blood samples for clearance determinations were obtained at the midpoint of $E_{2}$ and $E_{3}$, and the experiment terminated by collecting a 3-ml arterial blood sample into a chilled Vacutainer tube (Becton Dickinson \& Co., Rutherford, NJ) containing EDTA and $500 \mathrm{kal}-$ likrein inhibitory units (KIU) aprotinin at the end of $E_{3}$. This sample was centrifuged immediately at $4^{\circ} \mathrm{C}$ and the plasma decanted and stored at $-70^{\circ} \mathrm{C}$ for later determination of ANP concentration by radioimmunoassay (RIA).

This protocol was followed for each of three groups of experiments. Group I consisted of normal (group Ia, $n=7$ ) and nephrotic (group Ib, $n=6$ ) rats studied over an identical time period but not undergoing the $2 \%$ body weight saline infusion; they served as time control experiments for spontaneous variations in electrolyte excretion and to determine the basal, non-volume expanded ANP concentration in plasma. Group Ila consisted of 28 normal rats, and group IIb of 27 nephrotic rats, undergoing the volume expansion protocol described above. In group III rats we tested the effect of renal denervation on the response to volume expansion. Four normal (group IIIa) and eight nephrotic (group IIIb) rats underwent surgical denervation of each kidney via a midline abdominal incision 3-6 d before acute study; after the denervation, the renal pedicles were coated with $2 \mathrm{~N}$ phenol, and the abdominal wound closed with clips. An additional group of six normal and four denervated nephrotic rats underwent a modified volume expansion protocol designed to reproduce as closely as possible the model employed by DiBona and colleagues in an earlier publication using conscious rats (7). After control urine collections, volume expansion was effected by infusing normal saline, in an amount equal to $5 \%$ body weight over $30 \mathrm{~min}$ with a constant infusion pump; urine collections continued during the period of this infusion. After these acute studies, kidneys from 3 innervated and 11 denervated rats were harvested and frozen for later determination of renal norepinephrine content.

An additional group underwent the same short ( $2 \%$ body weight normal saline infusion over $5 \mathrm{~min}$ ) volume expansion protocol during intrarenal infusion of zaprinast (M\&B 22,948; Rhone-Padene Rorer, Dagenham, England), $10 \mu \mathrm{g} / \mathrm{min}$. Through a left paraspinal incision the left renal artery was exposed and a curved 30-gauge needle inserted near the junction of the artery with the aorta. Prompt return of arterial blood through the PE 10 tubing (Clay Adams, Parsippany, NJ) attached to the needle confirmed successful placement. The tubing was then attached to a syringe pump calibrated to deliver the zaprinast in normal saline containing $1 \mathrm{mg} / \mathrm{ml}$ each of bacitracin and bovine serum albumin at $10 \mu \mathrm{l} / \mathrm{min}$. The left ureter was cannulated with PE 50 tubing for urine collection; bladder urine reflected excretion from the right, contralateral kidney. After a 30-min period of stabilization following completion of surgery, the protocol described above for groups II and III was then carried out. 10 normal (group IVa) and 14 nephrotic (group IVb) rats were studied in this manner.

Electrolyte, urinary cGMP, and renal norepinephrine measurements. Urine flow rate was determined gravimetrically, and urine sodium and potassium concentrations were measured by flame photometry (model 943, Instrumentation Laboratories, Lexington, MA) with cesium as internal standard; the product of these concentrations and flow rate yielded sodium $\left(U_{N a} V\right)$ and potassium $\left(U_{K} V\right)$ excretion rates. Plasma and urine iothalamate concentrations were measured by fluorescence excitation (22), and the clearance calculated from the product of the urine-to-plasma concentration ratio and urine flow rate. For calculation of fractional sodium excretion $\left(\mathrm{FE}_{\mathrm{Na}}\right)$ the plasma sodium concentration was assumed to be $140 \mathrm{meq} / \mathrm{liter}$. Cyclic guanosine-3',5'-monophosphate (cGMP) was measured in unextracted urine in 21 group II ( 10 normal, 11 nephrotic) and 19 group IV ( 8 normal, 11 nephrotic) experiments, using a commercially available kit (New England Nuclear, Boston, MA). Samples were acetylated according to the manufacturer's instructions before assay. For determination of renal norepinephrine content, whole kidneys were homogenized in 0.1 $\mathrm{M} \mathrm{HClO}_{4}$ and the homogenate cleared by centrifugation. Internal standard (3,4-dihydroxybenzylamine) was added and the catecholamines separated on a $5-\mu \mathrm{m}$ octadecylsilane column $(4.6 \times 150 \mathrm{~mm}$; Axxiom Chomatography, Moorpark, CA ) developed isocratically at $35^{\circ} \mathrm{C}$ at a flow rate of $1.5 \mathrm{ml} / \mathrm{min}$. The mobile phase was a solution of sodium 
phosphate dibasic $(0.025 \mathrm{M})$ and hydrated citric acid $(0.025 \mathrm{M})$, to which $34 \mu \mathrm{l}$ of $\mathrm{Na}_{2}$ EDTA $(0.005 \mathrm{mM})$, and $70 \mathrm{mg}$ of octyl sodium sulfate were added. To $950 \mathrm{ml}$ of this buffer was added $40 \mathrm{ml}$ of methanol, $10 \mathrm{ml}$ of isopropanol, and $250 \mu \mathrm{l}$ of triethylamine. The mixture was then adjusted to final pH 3.9 by dropwise addition of phosphoric acid. Eluted catecholamines were detected electrochemically using a detector (Bioanalytical Systems Inc., W. Lafayette, IN). Quantitation was achieved using peak height ratios.

RIA of ANP concentration in plasma. Plasma samples were thawed in the cold and extracted with Sep Pak $\mathrm{C}_{18}$ cartridges (Waters Inc., Milford, MA) that had been preequilibrated with $0.1 \%$ trifluoroacetic acid (TFA) as described previously (23). The sample was eluted with $75 \%$ methanol in $0.1 \%$ TFA and then evaporated to dryness under a nitrogen stream; samples were stored at $-70^{\circ} \mathrm{C}$ until assayed. For the assay, the samples were reconstituted in assay buffer and ANP immunoreactivity measured in duplicate using commercially available antisera (Research and Diagnostics, Emeryville, CA), ${ }^{125} \mathrm{I}_{-} \mathrm{rANP}{ }_{1-28}$ labeled using the chloramine-T method, and unlabeled $\mathrm{rANP}_{1-28}$ as the standard. The characteristics of this assay have been reported in detail (23); the assay is sensitive to $5 \mathrm{pg}$ per tube, and intra- and interassay coefficients of variation are $5 \%$ and $16 \%$, respectively.

Measurement of cyclic nucleotide production by isolated glomeruli and IMCD cells. Glomeruli were isolated using a modification (24) of the technique of Chaumet-Riffaud et al. (25). Aliquots of the final centrifugation uniformly indicated a yield of material containing $>90 \%$ glomeruli with $<5 \%$ tubular contamination when examined by light microscopy. The pellet was resuspended in ice-cold $20 \mathrm{mM}$ Tris (hydroxymethylaminomethane) hydrochloride buffer, $\mathrm{pH} 7.4$, containing $135 \mathrm{mM} \mathrm{NaCl}, 10 \mathrm{mM} \mathrm{KCl}, 10 \mathrm{mM} \mathrm{Na}$ acetate, and $5 \mathrm{mM}$ glucose (buffer A) and aliquots used for the incubations described below. IMCD cells were isolated according to the method of Zeidel et al. (26) from collagenase-digested sections of inner medulla. Samples of IMCD cells from normal and nephrotic rat kidneys were then embedded in Poly/BED 812 and examined by transmission electron microscopy using a model 100 SC microscope (JEOL USA, Peabody, MA); photographs were made at $\times 6900$. Cells from both normal and nephrotic animals exhibited the characteristic ultrastructural appearance of IMCD cells including large nuclei and pale cytoplasm with few organelles (26); no differences between normal and nephrotic cells were observed.

For measurement of ANP-dependent cGMP accumulation, aliquots of fresh glomeruli or IMCD cells were suspended in $350 \mu \mathrm{l}$ of buffer $A$ containing $1 \mathrm{mM} \mathrm{CaCl}_{2}$ for glomeruli or $7.5 \mathrm{mM}$ glucose but no pyruvate or acetate for IMCD cells and preincubated for $10 \mathrm{~min}$ at $37^{\circ} \mathrm{C}$ in a shaking water bath. In some preparations, isobutylmethylxanthine (IBMX) or zaprinast, each at $10^{-3} \mathrm{M}$, was included in the incubation medium. Incubation was started by adding synthetic rat $\mathrm{ANP}_{1-28}$ (Peninsula Laboratories, Inc., Belmont, CA) in a concentration of $10^{-11}$ to $10^{-5} \mathrm{M}$, and terminated after $10 \mathrm{~min}$ by adding $750 \mu \mathrm{l}$ of ice cold trichloroacetic acid (TCA), final concentration $6.6 \%$, and cooling to $4^{\circ} \mathrm{C}$. The precipitated protein was sedimented by centrifugation at $4,500 \mathrm{rpm}$ for $15 \mathrm{~min}$ at $4^{\circ} \mathrm{C}$, and the pellet were dissolved in 1 $\mathrm{N} \mathrm{NaOH}$ and assayed for protein content by the method of Lowry et al. (27) using bovine serum albumin as the standard. The supernatant fluid was extracted five times with four volumes of water-saturated ethyl ether to remove the TCA before being evaporated to dryness under a stream of air; it was stored at $-70^{\circ}$ until assayed for cGMP content. For the cGMP assay, samples were dissolved in $50 \mathrm{mM}$ so-

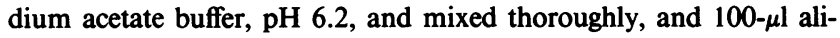
quots were acetylated according to the manufacturer's instructions (New England Nuclear). Averaged results of triplicate determinations are expressed as femtomoles CGMP accumulated per 10 min-incubation per milligram protein. This same procedure was also used to determine cGMP accumulation in response to sodium nitroprusside $\left(10^{-9}\right.$ to $10^{-5} \mathrm{M}$ ).

We also measured the ability of glomeruli and IMCD cells to generate cyclic AMP in response to vasopressin. Synthetic arginine vasopressin (AVP, Peninsula Laboratories, Inc.) was added to incubation medium (without IBMX) at concentrations of $10^{-11}$ to $10^{-5} \mathrm{M}$; the reac- tion was stopped after 10 min as described above and cAMP content assayed using a commercial kit (New England Nuclear).

Measurement of binding of ${ }^{125}$ I-ANP to IMCD cells. Freshly dispersed IMCD cells were resuspended in $400 \mu$ l of phosphate-buffered saline (PBS). Binding reactions were run in $200 \mu$ l of DME-H21, 0.2\% bovine serum albumin, $10 \mathrm{mM}$ Hepes buffer ( $\mathrm{pH} 7.4$ ), varying concentrations of ${ }^{125} \mathrm{I}$-ANP $\left(5 \times 10^{-12}\right.$ to $\left.10^{-9} \mathrm{M}\right)$, phosphoramidon ( 8 $\mu \mathrm{g} / \mathrm{ml}$ ) in the presence or absence of $10^{-6} \mathrm{M}$ unlabeled ANP. Reactions were initiated by the addition of $10 \mu \mathrm{l}$ of the cell suspension described above and run for $30 \mathrm{~min}$ at $37^{\circ} \mathrm{C}$. Cells were then pelleted, resuspended, washed with PBS four times at $4^{\circ} \mathrm{C}$, repelleted, and lysed in $1 \mathrm{~N} \mathrm{NaOH}(1 \mathrm{ml})$. A $900 \mu$ l aliquot was then taken for counting. Protein determinations were made using the Coomassie Blue reagent (Pierce Biochemicals, Rockford, IL).

Data presentation and statistical analysis. Data are presented as group means \pm 1 standard error (SE). For the clearance experiments, urinary variables were assessed using repeated measures analysis of variance with the Bonferroni post hoc test; since values from $C_{1}$ never differed significantly from $\mathrm{C}_{2}$, results in these two periods were pooled to provide a single control measurement in some analyses. Comparisons among groups utilized the unpaired $t$ test when only two groups were compared, and one way analysis of variance when three or more groups were involved. A $P$ value $<0.05$ was used to assign statistical significance.

\section{Results}

The modest volume expansion protocol used in group II experiments led to a brisk natriuresis in normal rats (group IIa) that was evident in the very first 10 -min postinfusion period $\left(E_{1}\right)$, peaked in the second period $\left(E_{2}\right)$ and then declined somewhat to a level in $\mathrm{E}_{3}$ which remained above the control (Fig. 1). In nephrotic rats (group IIb), an increase in $\mathrm{U}_{\mathrm{Na}} \mathrm{V}$ in response to the administered saline was also observed, although its magnitude was markedly blunted when compared to the normal rats (Fig. 1). More complete data from these studies as well as groups I and III are presented in Table I, where values from $\mathrm{C}_{1}$

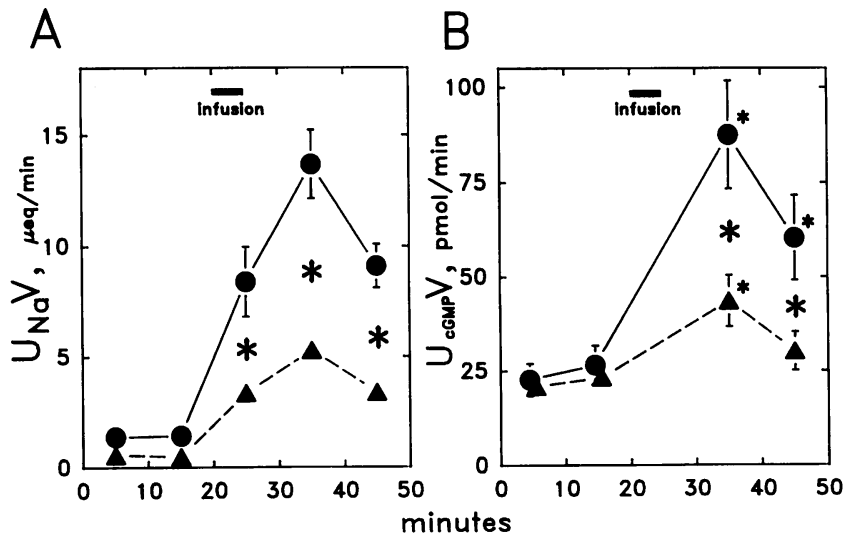

Figure 1. (A) Urinary sodium excretion after intravenous infusion of normal saline in 28 normal rats $(\bullet)$ and 27 rats with adriamycin nephrosis $(\Delta)$. Rats received a volume equal to $2 \%$ body weight over 5 min as indicated by the solid bar. Natriuresis after the infusion was significantly less in nephrotic rats at each 10 -min interval, as indicated by asterisks ( $P<0.02$ or less). $(B)$ Urinary cGMP excretion in 10 normal and 11 nephrotic rats after saline infusion. $U_{\text {CGMP }} V$ was significantly increased in normals in the second and third 10-min periods after the infusion $(P<0.01)$, and was also increased in the second period in nephrotics over control (small asterisks). However, nephrotic values were less than normals in both postinfusion periods $(P<0.005)$, as indicated by the large asterisks. 


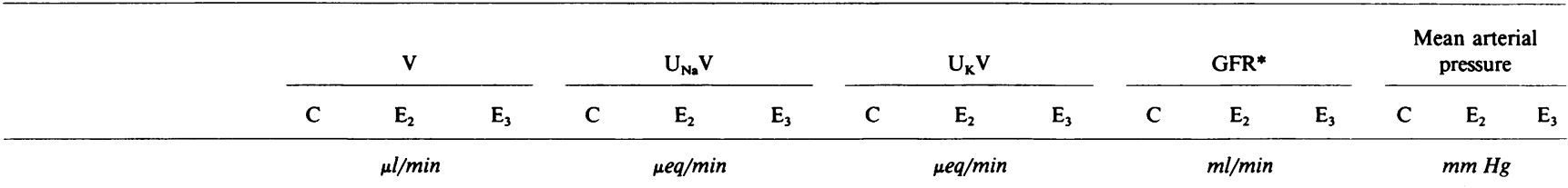

Group I: time control

$\begin{array}{lrrrrrrrrrrrrrrr}\text { Normal rats }(n=7) & & & & & & & & & & & & \\ \overline{\mathrm{X}} & 15.4 & 18.1 & 17.9 & 1.14 & 1.35 & 1.39 & 3.01 & 3.46 & 3.39 & 3.35 & 3.15 & 3.58 & 108 & 108 & 108 \\ \text { SE } & 3.3 & 3.5 & 2.8 & 0.44 & 0.49 & 0.46 & 0.63 & 0.70 & 0.40 & 0.26 & 0.37 & 0.40 & 5 & 5 & 5 \\ P & & \text { NS } & \text { NS } & & \text { NS } & \text { NS } & & \text { NS } & \text { NS } & & \text { NS } & \text { NS } & \text { NS } & \text { NS } \\ P \text { Nephrotic rats }(n=6) & & & & & & & & & & & & & & \\ \bar{X} & 10.0 & 9.4 & 12.5 & 0.68 & 0.57 & 0.83 & 2.12 & 1.77 & 2.37 & 1.65 & 2.62 & 2.97 & 113 & 113 & 113 \\ \text { SE } & 2.3 & 2.5 & 4.5 & 0.31 & 0.35 & 0.56 & 0.60 & 0.51 & 0.76 & - & - & - & 5 & 5 \\ P & & \text { NS } & \text { NS } & & \text { NS } & \text { NS } & & \text { NS } & \text { NS } & & & & \end{array}$

Group II: volume expansion, innervated kidneys

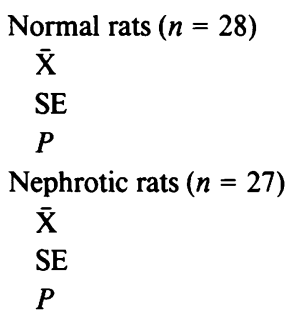

$\begin{array}{ccc}14.6 & 102.2 & 71.3 \\ 1.8 & 13.4 & 8.9 \\ & <.001 & <.001 \\ & & \\ 9.3^{\ddagger} & 40.4^{\ddagger} & 27.1^{\ddagger} \\ 0.9 & 4.3 & 3.2 \\ & <.001 & <.01\end{array}$

$\begin{array}{rrllllllllrr}1.38 & 13.69 & 9.10 & 2.45 & 4.06 & 3.18 & 2.79 & 3.47 & 2.89 & 110 & 110 & 110 \\ 0.29 & 1.54 & 0.98 & 0.23 & 0.35 & 0.24 & 0.17 & 0.27 & 0.26 & 2 & 2 & 2 \\ & <.001 & <.001 & & <.001 & <.005 & & <.01 & \text { NS } & & \text { NS } & \text { NS } \\ & & & & & & & & & & & \\ 0.51^{\ddagger} & 5.29^{\ddagger} & 3.36^{\ddagger} & 1.74^{\ddagger} & 3.33^{\ddagger} & 2.32^{\ddagger} & 2.02^{\ddagger} & 2.98 & 2.18^{\ddagger} & 123 & 121 & 120 \\ 0.09 & 0.51 & 0.28 & 0.17 & 0.3 & 0.22 & 0.16 & 0.31 & 0.21 & 3 & 2 & 3 \\ & <.001 & <.001 & & <.005 & <.05 & & <.01 & \text { NS } & & \text { NS } & \text { NS }\end{array}$

Group III: volume expansion, denervated kidneys

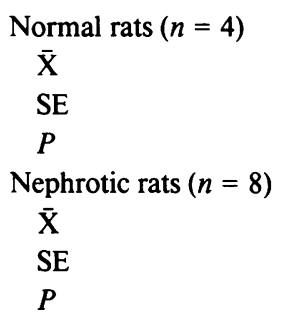

$\begin{array}{ccc}20.8 & 94.0 & 50.0 \\ 7.9 & 24.5 & 5.6 \\ & <.001 & <.01 \\ & & \\ 15.4^{\ddagger} & 40.1^{\ddagger} & 32.8^{\ddagger} \\ 1.7 & 7.7 & 5.8 \\ & <.01 & <.05\end{array}$

$\begin{array}{rrllllllllrr}1.42 & 14.76 & 8.72 & 2.06 & 3.19 & 2.38 & 2.00 & 2.50 & 2.20 & 108 & 108 & 105 \\ 0.39 & 5.09 & 1.52 & 0.72 & 0.33 & 0.24 & 0.63 & 0.39 & 0.5 & 3 & 3 & 3 \\ & <.001 & <.005 & & <.05 & \text { NS } & & <.05 & \text { NS } & & \text { NS } & \text { NS } \\ & & & & & & & & & & & \\ 0.20^{\ddagger} & 1.85^{\ddagger} & 1.96^{\ddagger} & 1.01^{\ddagger} & 3.39 & 2.55 & 1.59 & 2.85 & 1.68 & 94 & 94 & 95 \\ 0.04 & 0.51 & 0.49 & 0.16 & 0.6 & 0.45 & 0.3 & 0.49 & 0.22 & 6 & 6 & 5 \\ & <.005 & <.005 & & <.02 & <.05 & & <.05 & \text { NS } & & \text { NS } & \text { NS }\end{array}$

* GFR was measured in 4 rats in group Ia, 2 in group Ib, 24 in group IIa, and 23 in group Ilb. ${ }^{\ddagger}$ Significantly less than corresponding value in normals, $P<0.05$ or greater.

and $C_{2}$ have been averaged to compare with the values from $E_{2}$ and $E_{3}$. In rats undergoing the time-control study (groups Ia and $\mathrm{Ib}$ ), $\mathrm{U}_{\mathrm{Na}} \mathrm{V}$ remained stable; it was slightly, but not significantly, higher in normal than in nephrotic animals. The same was true of $U_{K} V$. GFR was unchanged over time in the normals; the increasing GFR seen in group Ib nephrotic time control rats likely reflects the limited number of animals in which the measurement was made $(n=2)$.

The consequences of the volume expansion protocol in group II rats are also shown in Table I. Group IIa normal rats had significantly greater control values for urine flow ( $P$ $=0.013), \mathrm{U}_{\mathrm{Na}} \mathrm{V}(P=0.006)$, and $\mathrm{U}_{\mathrm{K}} \mathrm{V}(P=0.016)$ than group IIb nephrotic animals and a modestly but significantly lower blood pressure. After the volume load, significant increases in all variables occurred in both groups with the exception of blood pressure, which did not change. However, the postinfusion value in urinary excretion observed in group IIb was in each case significantly less than in group IIa. Control GFR in group IIb was significantly less $(P=0.005)$ than in group IIa; after the saline infusion, large increases occurred in both groups in $\mathrm{E}_{2}$ and then returned to baseline control values in $\mathrm{E}_{3}$. The measured increase was comparable in both groups, but was not sufficient to prevent a large increase in fractional sodium excretion $\left(\mathrm{FE}_{\mathrm{Na}}\right)$ in each group, from $0.32 \pm 0.06 \%$ during control to $3.01 \pm 0.38 \%$ in $\mathrm{E}_{2}$ and $2.22 \pm 0.30 \%$ in $\mathrm{E}_{3}$ for group IIa rats ( $P<0.001$ for both), and from $0.24 \pm 0.07 \%$ during control to $1.49 \pm 0.23 \%$ in $\mathrm{E}_{2}$ and $1.22 \pm 0.14 \%$ in $\mathrm{E}_{3}$ for group IIb $(P<0.001$ for both $)$. However, just as with $\mathrm{U}_{\mathrm{Na}} \mathrm{V}, \mathrm{FE}_{\mathrm{Na}}$ in group IIb nephrotic rats was significantly less after saline infusion than in group IIa $(P=0.007)$.

The volume expansion protocol was also carried out in group III rats that had undergone prior renal denervation, and these results are also shown in Table I. Baseline urine flow, $\mathrm{U}_{\mathrm{Na}} \mathrm{V}$, and $\mathrm{U}_{\mathrm{K}} \mathrm{V}$ were greater $(P<0.02)$ in group IIIa denervated normal rats than in denervated nephrotic group IIIb animals, as had also been seen in group II. After volume expansion, increases in $\mathrm{U}_{\mathrm{Na}} \mathrm{V}$ occurred in both groups, but again, a distinct difference existed between the response of group IIIa 
normal and IIIb nephrotic rats, with the latter exhibiting a markedly blunted response. Indeed, the values in group IIIb of $1.85 \pm 1.45$ and $1.96 \pm 1.38 \mu \mathrm{eq} / \mathrm{min}$ in $E_{2}$ and $E_{3}$, respectively, after volume expansion were significantly less $(P<0.05)$ even than observed in group IIb. Changes in $\mathrm{FE}_{\mathrm{Na}}$ paralleled results in group II studies. In group IIIa denervated normal rats, $\mathrm{FE}_{\mathrm{Na}}$ increased from $0.69 \pm 0.17 \%$ during control to $4.00 \pm 0.79$ and $3.12 \pm 0.60 \%$ in $E_{2}$ and $E_{3}$, respectively, while in group IIIb, the corresponding values were $0.10 \pm 0.02,0.53 \pm 0.15$, and $1.00 \pm 0.33 \%$. These values in group IIIb were all significantly less than those in group IIIa $(P<0.007)$. In an effort to examine the effect of renal denervation more fully, we carried out a small number of experiments attempting to duplicate in part the protocol of DiBona et al. (7), in which a 5\% body weight isotonic saline infusion was administered over $30 \mathrm{~min}$ to conscious rats. In six anesthetized normal animals, $U_{\mathrm{Na}} V$ rose from a control value of $0.7 \pm 0.3$ to a peak value of $41.9 \pm 10.3$ $\mu \mathrm{eq} / \mathrm{min} 20 \mathrm{~min}$ after the onset of the infusion. In four anesthetized nephrotic rats that had undergone prior renal denervation, a blunted natriuretic response was again observed, $\mathrm{U}_{\mathrm{Na}} \mathrm{V}$ increasing only from $0.5 \pm 0.2$ to $10.8 \pm 7.0 \mu \mathrm{eq} / \mathrm{min}$, signifcantly less $(P<0.05)$ than the value in innervated normals. The adequacy of the renal denervation procedure was documented by measuring the renal content of norepinephrine in 6 innervated and 22 denervated kidneys. Renal content of norepinephrine was $123 \pm 25 \mathrm{pg} / \mathrm{mg}$ wet wt in innervated kidneys, and fell to $5.0 \pm 0.2 \mathrm{pg} / \mathrm{mg}$ wet wt in denervated kidneys. Thus, we were unable to demonstrate an amelioration of volume expansion natriuresis in this model of experimental nephrosis by renal denervation.

Fig. 2 presents the plasma ANP concentrations obtained at the conclusion of the experiment. In the group I time control experiments plasma immunoreactive ANP was similar in normal and nephrotic rats, $103 \pm 18$ and $89 \pm 26 \mathrm{pg} / \mathrm{ml}$, respectively. 30 min after volume expansion, it was significantly elevated over control in both normals and nephrotics, the value of $201 \pm 27 \mathrm{pg} / \mathrm{ml}$ in group Ila being greater than group Ia $(P$ $<0.05)$, and the value of $311 \pm 35$ in group IIb being greater than group $\mathrm{Ib}(P<0.005)$. Indeed, the group IIb value was also significantly greater than group IIa $(P=0.024)$, indicating that

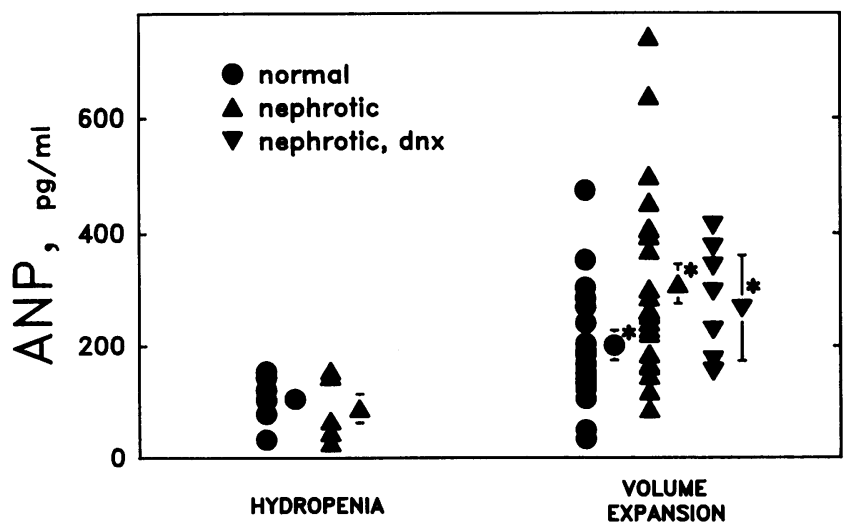

Figure 2. Plasma concentrations of immunoreactive ANP in normal and nephrotic rats 30 min after volume expansion (right) or continued hydropenia $(l e f t)$. Values are from 6 normal and 5 nephrotic animals during hydropenia, and 19 normal and 21 nephrotic rats after volume expansion. Also shown are results in eight nephrotic rats which had undergone prior bilateral renal denervation. the blunted natriuretic response in nephrotic animals was accompanied by an accentuation in the plasma ANP response and confirming the ANP "resistance" reported by others in experimental nephrosis. This was also true in group IIIb nephrotic rats with renal denervation, in which the ANP level was $267 \pm 36 \mathrm{pg} / \mathrm{ml}$, significantly greater than the value in group Ib and not different from group IIb. Plasma ANP concentration was not measured in group IIIa.

Nephrotic animals had reduced natriuresis after volume expansion despite higher concentrations of ir-ÁNP in plasma, raising the possibility of blunted ANP activity. To approach this question more directly, we measured the urinary excretion of cGMP as an index of the renal action of ANP. The results are shown in Fig. 1. Basal rates of $U_{\text {CGMP }} V$ were similar in normals and nephrotics, and increased in both as a consequence of the saline infusion. However, in the nephrotic animals the cGMP response was blunted, increasing to only $50 \%$ of the rate seen in normals during periods $E_{2}$ and $E_{3}$, and paralleling temporally the blunted natriuretic response (Fig. 1). These data support the hypothesis that responsiveness to ANP is impaired in nephrosis and imply that renal target sites are either inaccessible to the hormone or have a limited capability to trigger and maintain the signalling mechanism linked to it. To test the latter hypothesis, we isolated glomeruli and IMCD cells as described in Methods, incubated them with synthetic rat $\mathrm{ANP}_{1-28}$ across a wide concentration range, and quantitated the resultant changes in cGMP levels in the incubation medium. The results are shown in Fig. 3. Basal cGMP was similar in tissues from normal and nephrotic rats, and increased in response to added ANP in a dose-dependent manner. However, both glomeruli and IMCD cells from nephrotic rats had a blunted response when compared to normal. In normal glomeruli the peak cGMP response of $1,437 \pm 211 \mathrm{fmol} / \mathrm{mg}$ protein per 10 min occurred at an ANP concentration of $10^{-6} \mathrm{M}$. This value was roughly 10 times the basal value seen with vehicle alone, while in nephrotic glomeruli, it was only $482 \pm 92 \mathrm{fmol} / \mathrm{mg}$ protein per $10 \mathrm{~min}(P<0.002, n=5$ for each $)$, so that the ratio of normal to nephrotic was 2.98. Similar findings were obtained for IMCD cells (Fig. 3). Subsequent studies succeeded in localizing the defect to the biologically relevant (i.e., intracellular) compartment. In one set of experiments, vials were rapidly centrifuged at $4,000 \mathrm{rpm}$ for $1 \mathrm{~min}$ after the 10 -min incubation with ANP and the supernatant removed before adding TCA. cGMP measured after this procedure reflects predominantly intracellular cGMP; the ratio of cGMP produced ( $\mathrm{fmol} / \mathrm{mg}$ protein per $10 \mathrm{~min}$ ) in the presence of $10^{-6} \mathrm{M}$ ANP in normal vs. nephrotic glomeruli was $2.78(n=4, P<0.005)$ and in IMCD cells was $2.96(n=4, P<0.001)$.

This defect in cGMP production by nephrotic cells was not extrapolatable to other cyclic nucleotide signalling mechanisms. The production of cAMP in response to AVP was not different between normal and nephrotic kidneys in either glomeruli or IMCD cells (Fig. 4). Thus, impaired urinary excretion of cGMP by nephrotic rat kidneys in response to volume expansion in vivo was matched by blunted responsiveness of target cells to ANP in vitro, through a process specific for cGMP signaling pathway(s).

We next asked whether the refractoriness to ANP was reflected in an alteration in ANP receptor activity in normal vs. nephrotic cells. We selected IMCD cells for these studies because their receptor population is believed to consist largely of 


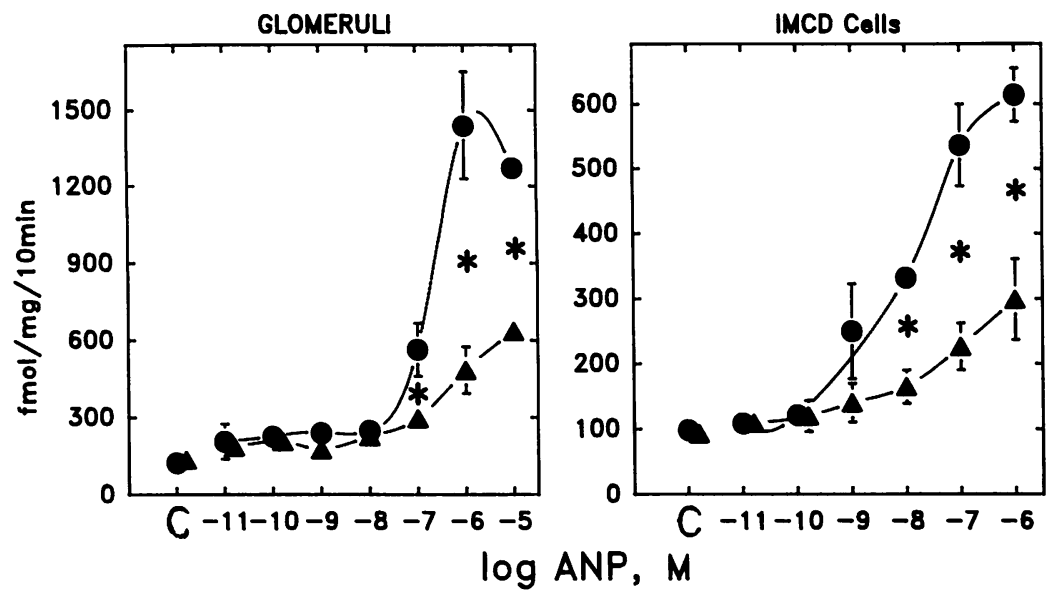

Figure 3. Accumulation of cGMP in the medium of isolated glomeruli (left) and IMCD cells ( right) incubated in vitro with ANP. In each case, basal cGMP accumulation did not differ between normals $(\bullet)$ and nephrotics $(\Delta)$, and dose-related increases occurred on incubation with ANP. However, accumulation of cGMP by nephrotic glomeruli and IMCD cells was significantly less than normals, as indicated by asterisks $(P<0.05$ or greater $)$. the guanylate cyclase-linked ANPR-A receptors $(28) .^{2}$ The difference observed in ANP sensitivity between normal and nephrotic cells was not attributable to differences in binding of ${ }^{125} \mathrm{I}-\mathrm{ANP}$ to IMCD cells. As shown in Table II, the calculated values for $\mathrm{B}_{\max }$ and $K_{\mathrm{D}}$ were not different for cells isolated from either normal or nephrotic kidneys, arguing that differences in ANP responsiveness must occur at a post-receptor locus.

Because the ANP-responsive A receptor and the guanylate cyclase catalytic activity reside in the same molecule, it seemed logical that the defect might lie distal to the synthesis of cGMP (e.g., at the level of cGMP degradation). To examine whether differences in activity of cyclic nucleotide phosphodiesterase (PDE) could account for the resistance to ANP, we challenged either glomeruli or IMCD cells with ANP in the presence of IBMX or zaprinast $\left(10^{-3} \mathrm{M}\right)$. We predicted that pharmacological inhibition of PDE would suppress or eliminate effects which operate through modulation of PDE activity. These results are presented in Fig. 5. Addition of IBMX to the incubation medium increased basal cGMP production, but again without appreciable differences between tissues from normal or nephrotic kidneys. The stimulation of cGMP production by ANP was amplified in the presence of IBMX in both IMCD cells and glomeruli from normal and nephrotic rats at $10^{-7}$ and $10^{-6} \mathrm{M}$. However, in both tissues, the difference between normals and nephrotics was no longer observed, as cGMP production by both glomeruli and IMCD cells from nephrotic kidneys was statistically indistinguishable from normal (Fig. 5). These data were paralleled by the results with zaprinast. The effect of this compound on basal cGMP accumulation was modest, but stimulation with $10^{-6} \mathrm{M}$ ANP was again amplified, and once again no difference between normal and nephrotic glomeruli or IMCD cells occurred. These findings imply that important differences in cGMP metabolism exist between normal and nephrotic animals, which may account, at least in part, for the resistance to ANP seen in the latter. To assess this possibility further, we measured cGMP accumulation in normal and nephrotic tissues in response to sodium nitroprusside, a compound which activates soluble guanylate cyclase rather than the particulate guanylate cyclase associated with the ANPR-A receptor. The results of studies in isolated glomeruli are pre-

2. Receptor classification according to Koller et al. (29). sented in Table III. Incubation with sodium nitroprusside caused a dose-dependent increase in cGMP accumulation by normal glomeruli, whereas accumulation by nephrotic glomeruli was blunted, the value at $10^{-5} \mathrm{M}$ being significantly less than in normals $(P<0.01)$. This difference between normals and nephrotics was abolished by addition of either IBMX or zaprinast at $10^{-3} \mathrm{M}$ ( Table III), thereby duplicating the results observed with ANP-stimulated cGMP accumulation. Exposure of IMCD cells to sodium nitroprusside led to qualitatively similar results, although responsiveness of these cells to the doses of nitroprusside used was much less than in glomeruli.

To determine if these in vitro observations were reflective of the phenomenon of ANP resistance in vivo, we carried out the volume expansion protocol in group IV rats in which zaprinast was infused into the left renal artery at $10 \mu \mathrm{g} / \mathrm{min}$. In Fig. $6 \mathrm{~A}$, data on $\mathrm{U}_{\mathrm{Na}} \mathrm{V}$ from each kidney (infused and contralateral) of 10 normal and 14 nephrotic rats are illustrated. Intrarenal zaprinast had a small effect on basal $\mathrm{U}_{\mathrm{Na}} \mathrm{V}$ in normal rats (ratio of infused/contralateral $1.50 \pm 0.32, P<0.01$ ) but increased it more strikingly in nephrotics (infused/contralateral $2.13 \pm 0.52, P<0.01)$. After volume expansion, $\mathrm{U}_{\mathrm{Na}} \mathrm{V}$ rose significantly from all kidneys, values in $E_{2}$ and $E_{3}$ being greater than each of the respective control periods by repeated measures ANOVA. In normal rats, zaprinast amplified volume expansion natriuresis modestly but significantly, the values of $\mathrm{U}_{\mathrm{Na}} \mathrm{V}$ in $\mathrm{E}_{2}$ and $\mathrm{E}_{3}$ again being greater from infused than contralateral kidneys $(P<0.01)$. The effect of zaprinast on volume

Table II. ANP Binding Activity in IMCD cells from Normal and Nephrotic Rats

\begin{tabular}{lcc}
\hline & $K_{d}$ & $B_{\max }$ \\
\hline & $M / l$ & mol/mg protein \\
Normal & $2.89 \pm 0.07 \times 10^{-11}$ & $2.47 \pm 0.03 \times 10^{-15}$ \\
Nephrotic & $5.70 \pm 1.00 \times 10^{-11}$ & $3.65 \pm 0.43 \times 10^{-15}$ \\
\hline
\end{tabular}

Values are means \pm 1 SE of measurements of specific binding of ${ }^{125} \mathrm{I}$ ANP to freshly dispersed IMCD cells as described in Methods. $B_{\max }$ has been corrected for protein content in the assay mixture. No significant difference in either $K_{\mathrm{d}}$ or $B_{\max }$ occurred between normal and nephrotic cells. 


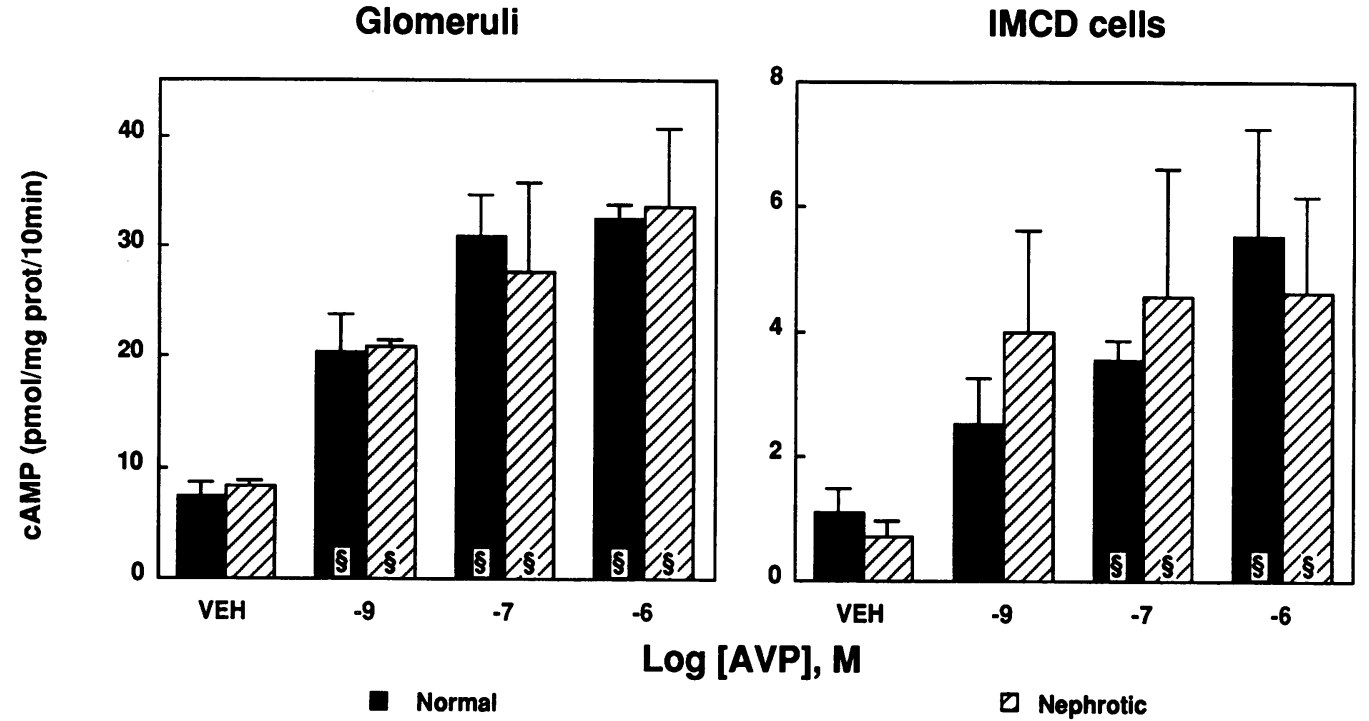

Figure 4. Accumulation of cAMP in response to AVP in isolated glomeruli (left) and IMCD cells (right) from normal and nephrotic rats. No differences in basal or stimulated cAMP accumulation occurred between normals and nephrotics. ${ }^{8}$ Signifcantly greater than value with vehicle alone, $P<0.05$. expansion natriuresis in nephrotic rats was more pronounced. Not only was $\mathrm{U}_{\mathrm{Na}} \mathrm{V}$ much greater from the infused kidney (infused/contralateral $2.62 \pm 0.51$ and $2.25 \pm 0.39$ for $E_{2}$ and $E_{3}$, respectively, $P<0.001$ for each), but the value from the infused kidneys was statistically indistinguishable from either infused or contralateral normal kidneys, and each was greater in $\mathrm{E}_{2}$ than the results from nephrotic contralateral (noninfused) kidneys $(P<0.05)$. Thus, intrarenal zaprinast was able to normalize volume expansion natriuresis by nephrotic kidneys.

The data on $\mathrm{U}_{\text {cGMP }} \mathrm{V}$ from 8 normal and 11 nephrotic group IV rats are shown in Fig. $6 \mathrm{~B}$. Qualitatively similar results were observed. Intrarenal zaprinast had no appreciable effect on baseline $\mathrm{U}_{\mathrm{CGMP}} \mathrm{V}$, and excretion again rose after volume expansion in all groups. $\mathrm{U}_{\mathrm{cGMP}} \mathrm{V}$ from contralateral nephrotic kidneys in $\mathrm{E}_{2}$ was less than from contralateral normal kidneys ( $28.35 \pm 3.27$ vs. $48.11 \pm 10.33 \mathrm{pmol} / \mathrm{min}, P=0.054)$, suggesting that the same defect observed in group IIb experiments existed in these group IVb animals as well. As with $\mathrm{U}_{\mathrm{Na}} \mathrm{V}$, zaprinast infusion completely normalized $U_{C G M P} V$ from nephrotic kidneys. These studies therefore indicate that zaprinast infusion in vivo is able to restore the blunted excretory response to volume expansion in nephrotic animals in a manner similar to its restoration of ANP responsiveness in vitro.

\section{Discussion}

Although some evidence suggests that sodium retention in nephrotic syndrome occurs in response to an underfilled circulation, compelling observations incriminate an abnormality intrinsic to the kidneys themselves to account for this defect. Nevertheless, the nature of this abnormality has remained obscure. The results of our experiments suggest that the defect in sodium metabolism in at least one form of experimental nephrosis, that resulting from adriamycin administration, may result from blunted cellular responsiveness to the renal actions of ANP. Other studies have documented that rats treated with adriamycin have a blunted natriuretic response to volume expansion (7) and ANP infusion (19-21). In recent studies, renal denervation improved both the volume expansion natriuresis (7) and the natriuresis resulting from infusion of ANP
(19), suggesting that the heightened sympathetic efferent renal nerve activity observed in this model of nephrosis (7) could contribute to abnormal sodium metabolism, and perhaps the ANP resistance which characterizes this and other forms of pathological sodium retention (30). In the present study we sought to investigate the regulation of sodium metabolism in nephrotic syndrome in the context of the resistance to ANP reported by others. In that infusion of ANP produces complex effects on the circulation and body fluid balance by virtue of its potent extrarenal as well as renal actions, we chose to use the technique of acute extracellular fluid volume expansion as a probe of integrated sodium-regulating mechanisms in nephrotic syndrome. Our experiments were in large measure successful for this purpose. Rapid intravenous infusion of a small volume of normal saline, equal to $2 \%$ of the rat's weight, caused an immediate, large diuresis and natriuresis in normal rats that was accompanied $25 \mathrm{~min}$ after the end of the infusion by a level of ANP in plasma that was on average twice the value seen in hydropenic rats. Subjected to this same infusion, rats with adriamycin nephrosis exhibited a significantly reduced natriuretic response despite an even higher level of ANP in plasma, suggesting resistance to the hormone at its peripheral target tissues. However, in contrast to the study alluded to above (7), we were unable to improve the natriuresis by renal denervation. The basis for this difference in outcomes is likely related to experimental design, because our experiments were conducted in anesthetized rats whereas those of DiBona and associates were carried out in conscious animals (7). Also, in our experiments, group IIIb denervated nephrotics had modestly but significantly reduced GFR and mean arterial pressure compared to group IIa normal rats, which could have obscured an ameliorative effect of the denervation on volume expansion natriuresis. Consequently, our data do not rule out a role of the renal nerves in contributing to abnormal sodium handling in nephrotic syndrome. Nevertheless, under our experimental conditions, the excretory defect was still present despite renal denervation, suggesting the presence of another abnormality in this model of nephrosis in contributing to abnormal renal sodium handling. We therefore sought other renal mechanisms that might account for it. Nephrotic animals had a statistically 
Glomeruli
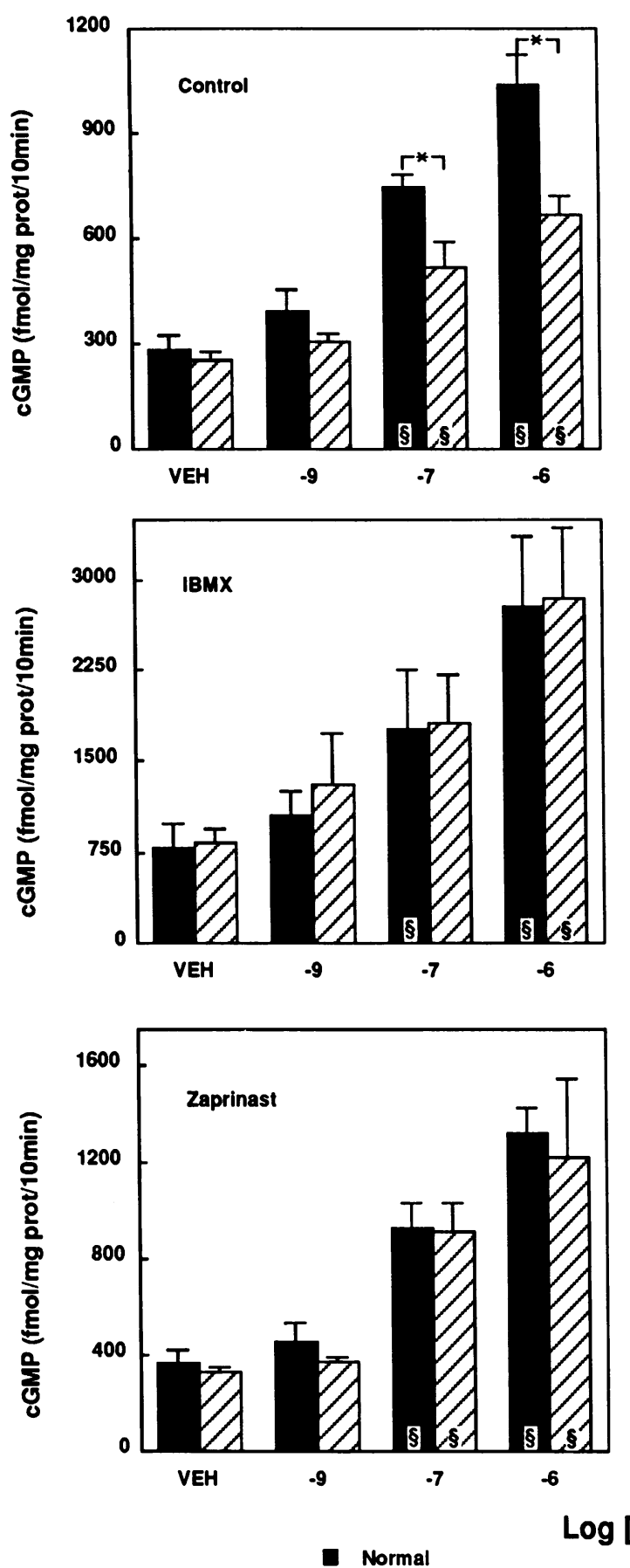
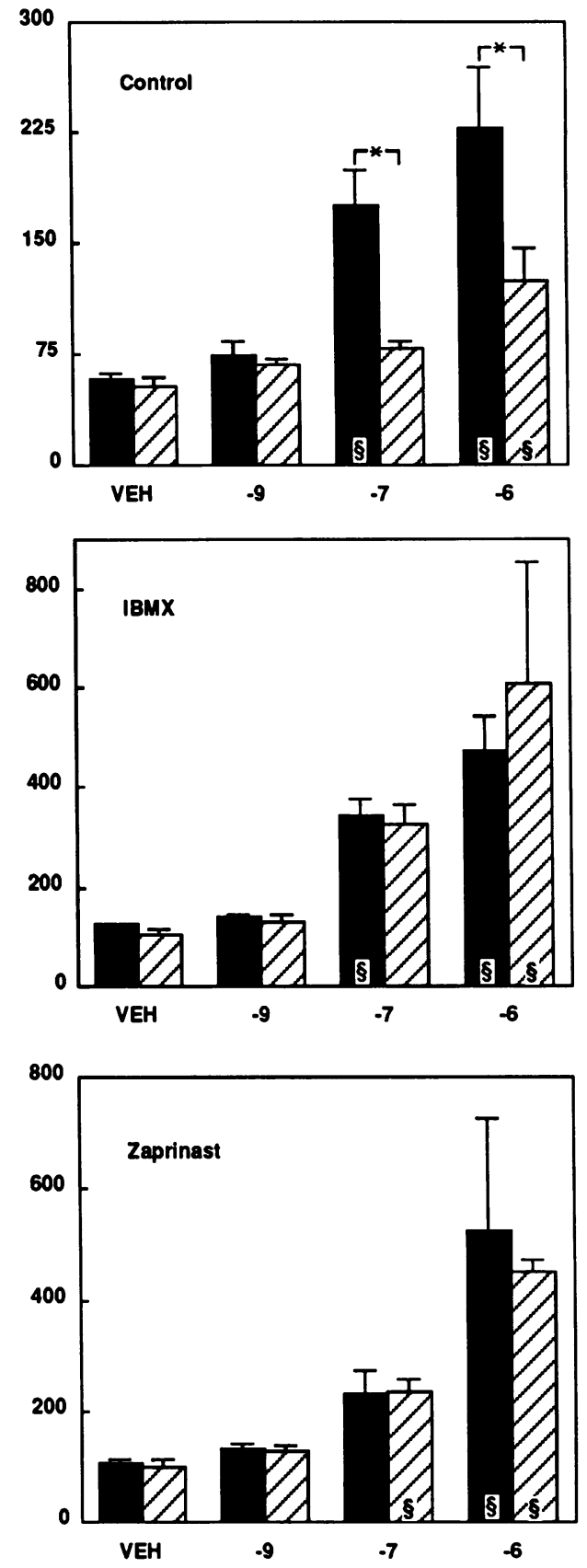

Dephrotic
Figure 5. Accumulation of cGMP by isolated glomeruli (left) and IMCD cells (right) from normal and nephrotic rats incubated with vehicle alone (top), IBMX (middle), or zaprinast (bottom). The concentration of each of the PDE inhibitors was $10^{-3} \mathrm{M}$. The blunted ANP-dependent cGMP accumulation seen in nephrotic compared to normal tissues incubated with vehicle alone was abolished in the presence of each of the

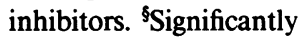
greater than same tissue without ANP, $P<0.05$; *significant difference between normals and nephrotics, $P$ $<0.05$. lower GFR than normals, which could have contributed to the blunted natriuresis. However, this does not seem likely. We identified nine nephrotic rats with mean GFR during control, $E_{2}$, and $E_{3}$ which were virtually identical to the values in normals; $\mathrm{U}_{\mathrm{Na}} \mathrm{V}$ in these nephrotic animals after volume expansion was still significantly reduced $(5.06 \pm 0.76$ and $3.35 \pm 0.62 \mu \mathrm{eq} /$ min in $E_{2}$ and $E_{3}$, respectively, both less than the respective values in normals, $P<0.02$ ). Moreover, the increase in GFR after the volume expansion was not different in both group IIa normal and group IIb nephrotic rats (Table I).

The finding of reduced excretion of cGMP after volume expansion in nephrotic rats despite elevated plasma ANP levels suggested that a defect in this humoral system might contribute to the abnormal response to volume expansion. At present, cGMP is the only recognized intracellular messenger of ANP in target tissues, including the kidney (31), and the urinary excretion of cGMP is believed to be an accurate reflection of ANP action within the kidney (23). The studies employing isolated glomeruli and IMCD cells incubated with ANP in vitro clearly show that cells from nephrotic kidneys exhibit an impaired ability to accumulate cGMP that closely parallels the reduced $\mathrm{U}_{\mathrm{CGMP}} \mathrm{V}$ shown by nephrotic rats after volume expansion. Ba- 
Table III. Accumulation of cGMP after Incubation with Sodium Nitroprusside by Isolated Glomeruli from Normal and Nephrotic Rats

\begin{tabular}{cccc}
\hline $\mathrm{NaP}(M)$ & Control & IBMX & Zaprinast \\
\hline \multicolumn{4}{c}{ fmol/mg protein per $10 \mathrm{~min}$}
\end{tabular}

Normal glomeruli

$\begin{array}{llll}(n=5) & & & \\ 0 & 140.6 \pm 18.2 & 919.9 \pm 345.6 & 262.2 \pm 74.6 \\ 10^{-9} & 265.0 \pm 56.9 & 1388.8 \pm 523.8 & 335.6 \pm 93.9 \\ 10^{-7} & 342.1 \pm 95.4^{*} & 1749.3 \pm 703.2 & 465.1 \pm 97.7 \\ 10^{-5} & 520.8 \pm 65.4^{*} & 3031.1 \pm 833.6^{*} & 802.4 \pm 212.6^{*}\end{array}$

Nephrotic glomeruli $(n=5)$

$\begin{array}{llll}0 & 125.5 \pm 29.5 & 937.7 \pm 305.4 & 260.8 \pm 30.5 \\ 10^{-9} & 179.7 \pm 33.8 & 1122.3 \pm 340.4 & 328.0 \pm 45.5 \\ 10^{-7} & 208.0 \pm 66.5 & 1530.8 \pm 465.9 & 450.7 \pm 86.3 \\ 10^{-5} & 280.3 \pm 21.8^{*} \neq & 3460.5 \pm 885.2^{*} & 831.7 \pm 226.5^{*}\end{array}$

Values are means \pm 1 SE of cGMP accumulation. IBMX and zaprinast were at $10^{-3} \mathrm{M}$. NaP, sodium nitroprusside. * Significantly greater than value with $0 \mathrm{NaP}, P<0.05$ by repeated measures ANOVA. ${ }^{\ddagger}$ Significantly less than corresponding value in normals, $P=0.008$.

sal cGMP production by these tissues in the absence of added ANP did not differ from normals, again paralleling control values for $U_{\mathrm{cGMP}} V$ in vivo, and suggesting that the nephrotic defect was confined to ANP-stimulated cGMP production. This was further supported by the observation that AVP-dependent cAMP production was normal in both glomeruli and IMCD cells from nephrotic kidneys, indicating that this peptide hormonal response system was not impaired by adriamycin treatment. The doses of ANP required to stimulate cGMP were far higher than the measured dissociation constant of the ANP-responsive A receptor in this and other systems (31). This discrepancy has been observed by others in a number of in vitro studies $(26,32,33)$, and awaits definitive explanation. In our system at least a portion of this reduction in efficacy may reflect degradation of ANP by endogenous peptidases.

Thus, these findings provide a means to link the blunted volume expansion natriuresis, known to occur in nephrotic syndrome (7), to the previously demonstrated resistance to infused ANP (19-21) through a cellular defect in the accumulation of its intracellular second messenger (i.e., cGMP) in responsive tissues. We attempted to explore the nature of this defect more fully by examining some of the determinants of cGMP levels. The existence of the particulate guanylate cyclase on the same molecule as the receptor with greatest affinity for ANP $(29,31)$ suggested the possibility that a reduction in cGMP accumulation could be related to a defect in binding of the peptide to its receptor. However, we could detect no difference in the binding characteristics of ${ }^{125} \mathrm{I}$-ANP to isolated IMCD cells from nephrotic vs. normal kidneys. These results agree with those of Perico and colleagues (18), and suggest that the abnormality lies at a postreceptor locus. The kidney contains a large number of ANP receptors that are biologically silent and not linked to guanylate cyclase (31), the ANPR-C or clearance receptors. If present in large numbers, relative to the guanylate cyclase-linked A receptors, $\mathrm{C}$ receptors could conceivably mask an abnormality in binding to the latter. While this might theoretically complicate interpretation of glomerular binding data, it is unlikely to explain our findings with IMCD cells, in that ANP receptors in these cells are thought largely to be of the biologically active (i.e., $\mathrm{A}-$ ) subtype (28). We then sought to determine if enhanced degradation of the cellular cGMP produced by a normal interaction between ANP and the receptor-cyclase complex could account for the impaired cGMP levels we observed in nephrotic tissues. We used IBMX, a general inhibitor of cyclic nucleotide PDEs, and zaprinast, an agent more specific for CGMP PDE (34), for this purpose. IBMX increased basal, nonstimulated levels of cGMP in both glomeruli and IMCD cells. Again, there was no difference in basal cGMP production between normals and nephrotics. As expected, cGMP levels in the presence of $10^{-6} \mathrm{M}$ ANP were elevated over levels from the same preparations incubated in the absence of IBMX. Zaprinast produced similar results, although levels with this compound were less elevated in glomeruli than with IBMX $(P<0.05)$. However, a major difference was seen in the presence vs. the absence of these two PDE inhibitors. After incubation with each inhibitor, the reduction in cGMP levels after exposure to ANP in cells from nephrotic tissues was virtually eliminated. Such results would therefore suggest that enhanced PDE activity contributes to the nephrotic abnormality in cGMP metabolism. This conclusion is further supported by the experiments in which cGMP production was stimulated with sodium nitroprusside, an activator of soluble guanylate cyclase. Accumulation of cGMP during incubation with this agent was also blunted in nephrotic compared to normal glomeruli, and was also totally corrected with either PDE inhibitor (Table III). IBMX is a nonspecific inhibitor of PDEs, yet we saw no difference in nephrotics with respect to AVP-dependent cAMP stimulation. This finding suggests the possibility that differential metabolism of cyclic

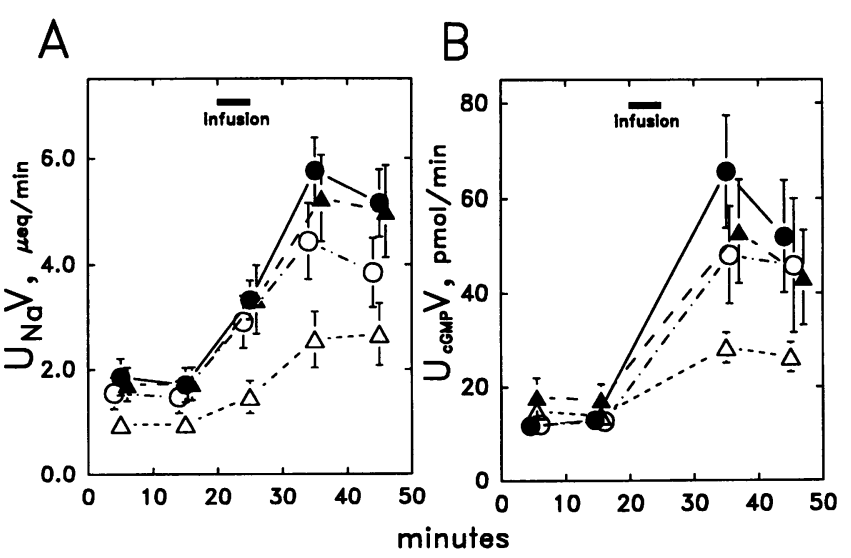

Figure 6. $(A)$ Urinary sodium excretion after volume expansion from left (solid symbols) and right (open symbols) kidneys of 10 normal (circles) and 14 nephrotic (triangles) rats. $(B)$ Urinary cGMP excretion from kidneys in 8 of the same normal and 11 nephrotic experiments. Left kidneys received a continuous infusion of zaprinast, 10 $\mu \mathrm{g} / \mathrm{min}$. The solid bar indicates the period of infusion of normal saline ( $2 \%$ body weight intravenously). Right kidneys from nephrotic rats $(\Delta)$ exhibited blunted natriuresis and $U_{C G M P} V$. Zaprinast-infused left kidneys had responses of each variable that were indistinguishable from normal kidneys. 
nucleotides in normal vs. nephrotic cells might be confined to a specific cGMP PDE (35), an hypothesis supported by the results with zaprinast, a compound with selectivity for this PDE isoform (34). Direct measurement of this enzyme activity in normal and nephrotic glomeruli and IMCD cells will be an important test of this hypothesis.

To test the physiological relevance of these in vitro observations, we carried out the volume expansion protocol in rats receiving an intrarenal infusion of zaprinast. The volume expansion natriuresis was somewhat more robust from normal kidneys infused with zaprinast, a response also observed by Wilkins and associates (34). However, a much more striking effect was seen in nephrotic kidneys. The contralateral, noninfused kidney exhibited blunted volume expansion natriuresis as was observed in group IIb studies. The natriuretic response of the infused kidney, however, was much greater and, in fact, could not be distinguished from the normal response. These results were qualitatively duplicated with respect to $U_{\mathrm{CGMP}} V$. In aggregate, they offer strong support for the biologic importance of enhanced cGMP PDE activity as the basis for ANP resistance observed in vitro.

Our data do not allow definition of the relative contributions of the glomerular vs. IMCD cell defect in ANP-stimulated cGMP accumulation to the blunted natriuresis seen in nephrotic animals. Some data link natriuresis after ANP infusion to the increase in GFR $(36,37)$, but there is strong evidence (reviewed in reference 31 ) pointing to direct inhibition of sodium transport in the IMCD. In our experiments, GFR rose after volume expansion in nephrotic animals to an extent similar to that seen in normals despite the impaired ANP-dependent cGMP accumulation that we observed in in vitro studies. Because there are multiple neural, humoral, and hemodynamic determinants of GFR that could be altered by volume expansion, the functional consequence of the in vitro defect could well be obscured, or not large enough to prevent ANPmediated hyperfiltration. However, to the extent that the changes in GFR in the two groups were comparable, our data suggest that the IMCD is the more likely of the two to represent the site responsible for blunted ANP-dependent natriuresis in adriamycin nephrosis. This conclusion fits with additional observations implicating a distal nephron locus for increased sodium reabsorption in nephrosis $(1,9-12)$.

In summary, we have identified an abnormality in cGMP metabolism in nephrotic rat glomeruli and IMCD cells in vitro which may account, at least in part, for the blunted volume expansion natriuresis and resistance to infused ANP found in vivo. Such an abnormality lends support to the contention that a component of nephrotic edema results from an intrarenal defect leading to salt retention. The present studies suggest the possibility that resistance to ANP may be related to enhanced activity of cGMP-PDE(s). Further study of this defect should provide new insight into the basis for pathological sodium retention in nephrotic syndrome.

\section{Acknowledgments}

The authors acknowledge the technical assistance of Sue Montgomery, R.N., and the secretarial support of Maria Narvaez. Zaprinast (M\&B 22,948 ) was courteously provided by the Dagenham Research Center of Rhone-Poulenc, Ltd. The authors are grateful to Dr. Li Cao for performing the ANP binding studies, and to Dr. Robert Kuhn for measuring renal norepinephrine content.

This work was supported by grants DK-31623 and HL35753 from the National Institutes of Health and by grants-in-aid 891124 and 901314 from the American Heart Association. Dr. Valentin was supported by fellowships from ICI Pharma and the American Heart Association, California Affiliate. Dr. Muldowney was the recipient of a matching fellowship from the National Kidney Foundation and the National Kidney Foundation of Northern California. Dr. Gardner is an Established Investigator of the American Heart Association.

\section{References}

1. Bernard, D. B. 1988. Extrarenal complications of the nephrotic syndrome. Kidney Int. 33:1184-1202.

2. Meltzer, J. I., H. J. Keim, J. H. Laragh, J. E. Sealey, K.-M. Jan, and S. Chien. 1979. Nephrotic syndrome: vasoconstriction and hypervolemic types indicated by renin-sodium profiling. Ann. Intern. Med. 92:688-696.

3. Chonko, A. M., W. H. Bay, J. H. Stein, and T. F. Ferris. 1977. The role of renin and aldosterone in the salt retention of edema. Am. J. Med. 63:881-889.

4. Kelsh, R. C., G. S. Light, and W. J. Oliver. 1972. The effect of albumin infusion upon plasma norepinephrine concentration in nephrotic children. $J$. Lab. Clin. Med. 79:516-525.

5. Gur, A., Y. P. Adefuin, N. J. Siegel, and J. P. Hayslett. 1976. A study of the renal handling of water in lipoid nephrosis. Pediatr. Res. 10:197-201.

6. Peterson, C., B. Madsen, A. Perlman, A. Y. M. Chan, and B. D. Myers. Atrial natriuretic peptide and the renal response to hypervolemia in nephrotic humans. Kidney Int. 34:825-831.

7. DiBona, G. F., P. J. Herman, and L. L. Sawin. 1988. Neural control of renal function in edema forming states. Am. J. Physiol. 254:R1017-R1024.

8. Krishna, G. G., and G. M. Danovitch. 1982. Effects of water immersion on renal function in the nephrotic syndrome. Kidney Int. 21:395-401.

9. Wagnild, J. P., and F. D. Gutmann. 1965. Functional adaptation of nephrons in dogs with acute progressing to chronic experimental glomerulonephritis. J. Clin. Invest. 57:1575-1589.

10. Grausz, H., R. Lieberman, and L. E. Earley. 1972. Effect of plasma albumin on sodium reabsorption in patients with nephrotic syndrome. Kidney Int. $1: 47-54$.

11. Bernard, D. B., E. A. Alexander, W. G. Couser, and N. G. Levinsky. 1978. Renal sodium retention during volume expansion in experimental nephrotic syndrome. Kidney Int. 14:478-485.

12. Ichikawa, I., H. G. Rennke, J. R. Hoyer, K. F. Badr, N. Schor, J. L. Troy, C. P. Lechene, and B. M. Brenner. 1983. Role for intrarenal mechanisms in the impaired salt excretion of experimental nephrotic syndrome. J. Clin. Invest. 71:91-103.

13. Brown, E. A., N. D. Markandu, G. A. Sagnella, M. Squires, B. E. Jones, and G. A. MacGregor. 1982. Evidence that some mechanism other than the renin system causes sodium retention in the nephrotic syndrome. Lancet. $i: 1237-1240$.

14. Dorhout Mees, E. J., C. J. Roos, P. Boer, C. H. Yoe, and T. A. Simatupang. 1979. Observations on edema formation in the nephrotic syndrome in adults with minimal lesions. Am. J. Med. 67:378-384.

15. Geers, A. B., H. A. Koomans, J. C. Roos, P. Boer, and E. J. Dorhout Mees. 1984. Functional relationships in the nephrotic syndrome. Kidney Int. 26:324330.

16. Frenk, S., I. Antonowicz, J. M. Craig, and J. Metcoff. 1955. Experimental nephrotic syndrome induced in rats by aminonucleoside: renal lesions and body electrolyte composition. Proc. Soc. Exp. Biol. Med. 89:424-427.

17. Bertani, T., A. Poggi, R. Pozzone, F. Delaini, G. Sacchi, Y. Thoua, G. Mecca, G. Remuzzi, and M. B. Donati. 1982. Adriamycin-induced nephrotic syndrome in rats. Sequence of pathologic events. Lab. Invest. 46:16-23.

18. Perico, N., F. Delaini, C. Lupini, A. Benigni, M. Galbusera, P. Boccardo, and $G$. Remuzzi. 1989. Blunted excretory response to atrial natriuretic peptide in experimental nephrosis. Kidney Int. 36:57-64.

19. Koepke, J. P., and G. F. DiBona. 1987. Blunted natriuresis to atrial natriuretic peptide in chronic sodium-retaining disorders. Am. J. Physiol. 252:F865F871.

20. Perico, N., F. Delaini, C. Lupini, and G. Remuzzi. 1987. Renal response to atrial peptides is reduced in experimental nephrosis. Am. J. Physiol. 252:F654 F660.

21. Hildebrandt, D. A., and R. O. Banks. 1988. Effect of atrial natriuretic factor on renal function in rats with nephrotic syndrome. Am. J. Physiol. 254:F210-F216.

22. Guesry, P., L. Kaufman, S. Orloff, J. A. Nelson, S. Swarm, and M. Holliday. 1975. Measurement of glomerular filtration rate by fluorescent excitation of nonradioactive meglumine iothalamate. Clin. Nephrol. 3:134-139.

23. Wong, K. R., M.-H. Xie, L.-B. Shi, F.-Y. Liu, C.-L. Huang, D. G. 
Gardner, and M. G. Cogan. 1988. Urinary cGMP as biological marker of the renal activity of atrial natriuretic factor. Am. J. Physiol. 255:F1220-F1224.

24. Don, B. R., S. Blake, F. N. Hutchinson, G. A. Kaysen, and M. Schambelan. 1989. Dietary protein modulates glomerular eicosanoid production in the rat. Am. J. Physiol. 256:F711-F718.

25. Chaumet-Riffaud, P., J.-P. Oudinet, J. Sraer, C. Lajotte, and R. Ardaillou. 1981. Altered $\mathrm{PGE}_{2}$ and $\mathrm{PGF}_{2 \alpha}$ production by glomeruli and papilla of sodiumdepleted and sodium-loaded rats. Am. J. Physiol. 241:F517-F524.

26. Zeidel, M. L., P. Silva, B. M. Brenner, and J. L. Seifter. 1987. cGMP mediates effects of atrial peptides on medullary collecting duct cells. Am. J. Physiol. 252:F551-F559.

27. Lowry, O. H., N. J. Rosebrough, A. L. Farr, and R. J. Randall. 1951 Protein measurement with the Folin phenol reagent. J. Biol. Chem. 193:265275.

28. Martin, E. R., J. A. Lewicki, R. J. Scarborough, and B. J. Ballermann 1989. Expression and regulation of ANP receptor subtypes in rat renal glomeruli and papillae. Am. J. Physiol. 257:F649-F657.

29. Koller, K. J., D. G. Lowe, G. L. Bennett, N. Minamino, K. Kangawa, H. Matsuo, and C. V. Goeddel. 1991. Selective activation of the B natriuretic peptide receptor by C-type natriuretic peptice (CNP). Science (Wash. DC). 252:120123.

30. Fried, T. A. 1989. Atrial natriuretic peptide in edematous states. In Atrial Natriuretic Peptides. Contemp. Issues Nephrol. 21:209-238.
31. Brenner, B. M., B. J. Ballerman, M. E. Gunning, and M. L. Zeidel. 1990 Diverse biological actions of atrial natriuretic peptide. Physiol. Rev. 70:665-699.

32. Nonoguchi, H., M. A. Knepper, and V. C. Manganiello. 1987. Effects of atrial natriuretic factor on cyclic guanosine monophosphate and cyclic adenosine monophosphate accumulation in microdissected nephron segments from rats. $J$. Clin. Invest. 79:500-507.

33. Stokes, T. J., C. L. McConkey, and K. J. Martin. 1986. Atriopeptin III increases CGMP in glomeruli but not in proximal tubules of dog kidney. $A m$. $J$. Physiol. 250:F27-F31.

34. Wilkins, M. R., S. L. Settle, and P. Needleman. 1990. Augmentation of the natriuretic activity of exogenous and endogenous atriopeptin in rats by inhibition of guanosine $3^{\prime}, 5^{\prime}$-cyclic monophosphate degradation. J. Clin. Invest. 85:1274-1279.

35. Conti, M., S.-L. C. Jin, L. Monaco, D. R. Repaske, and J. V. Swinnen. 1991. Hormonal regulation of cyclic nucleotide phosphodiesterases. Endocr. Rev 12:218-234.

36. Cogan, M. G. 1986. Atrial natriuretic factor can increase renal solute excretion primarily by raising glomerular filtration. Am. J. Physiol. 250:F710F714.

37. Wong, K. R., and M. G. Cogan. 1987. Comparison of the natriuresis and chloruresis associated with glomerular hyperfiltration induced by atrial natriuretic factor or glucagon. Life Sci. 40:1595-1600. 